\title{
MÚSICA E EDUCAÇÃO: ANTIGAS QUESTÕES, NOVOS DESAFIOS
}

\section{MUSIC AND EDUCATION: OLD ISSUES, NEW CHALLENGES}

Luciana Requião*

Resumo: O texto busca debater a questão da formação do professor de música frente aos desafios impostos pela Lei 11.769/08, que dispõe sobre a obrigatoriedade do ensino de música nas escolas de ensino básico como componente curricular obrigatório da disciplina de artes. $\mathrm{O}$ veto ao artigo $2^{\circ}$ da lei, que previa a necessidade de formação específica para o professor de música, acirra o antigo debate sobre a qualificação necessária ao profissional que será o responsável pelo ensino de música nas escolas. Por intermédio de estudo de caso em escolas da Costa Verde Sul Fluminense, observamos que a educação musical é percebida na maioria das vezes como um componente auxiliar para outras disciplinas ou como um elemento lúdico desprovido de conteúdos específicos, o que torna confusa a concepção de quem seria esse professor. Não obstante a falta de recursos materiais e humanos, tal realidade aponta para a necessidade de ações educativas que qualifiquem todo o processo histórico em que a educação musical passa a ser reconhecida como área de conhecimento específico. Assim, buscamos destacar que a Lei 11.769/08 necessita de ações que a tornem possível, e que para isso é necessário uma investigação mais profunda sobre a realidade das escolas brasileiras.

Palavras-chave: Música e educação. Lei 11.769/08.Formação de professores.

Abstract: The article discusses the education of music teachers, and the new challenges brought by the Law 11.769/08, and its imposition of musical education in elementary schools as part of the mandatory curriculum of the arts subject. The veto to the second article of this law, which foresaw the need of specific training to music teachers, revives the debate on the required training to the professional in charge of the musical teaching in these schools. Through case studies in schools of the Costa Verde Sul Fluminense, it was noticed that musical instruction was complementary to other subjects or a playful element devoid of any specific content knowledge, and that adds confusion to the conception about who should teach this subject. Despite the lack of human and specific material resources, such reality indicates the need for educative measures that qualify all the historical process in which musical education can be recognized as an area of specific knowledge. Thus, the article tries to emphasize that the Law 11.769/08 needs actions that turn it into a reality; for this to happen broader investigations of Brazilian school realities are necessary.

Keywords: Music and education. Law 11.769/08. Teacher education.

\footnotetext{
* Doutora em Educação pela UFF. Professora do Instituto de Educação Angra dos Reis, da UFF.

E-mail: <lucianarequiao@id.uff.br>.

* Doctor in Education from UFF. Professor at the Angra dos Reis Institute of Education, UFF.

E-mail: <lucianarequiao@id.uff.br>.
} 


\section{Introdução}

O dia 18 de agosto de 2008, quando foi sancionada a Lei $\mathrm{n}^{\circ} 11.769$ que dispõe sobre a obrigatoriedade do ensino de música nas escolas de ensino básico como componente curricular obrigatório da disciplina artes (BRASIL, 2008), constitui, sem dúvida, um marco histórico, particularmente para a área da Educação Musical no Brasil.Esse fato representa mais uma etapa de um processo,no qual antigas questões vêm sendo debatidas frente a novos desafios que cada um desses momentos históricos proporciona. Entre essas questões, por exemplo, estão o reconhecimento da música como área de conhecimento específico e a necessidade de formação específica para o professor de música.

A fundação do Conservatório de Música do Rio de Janeiro, em 1847,é considerada um dos marcos desse processo histórico, na direção da dissociação institucionalda educação musical dos serviços religiosos e, posteriormente,em sua constituição como área de conhecimento. De acordo com Oliveira

Durante os três primeiros séculos, após a descoberta pelos portugueses em 1500, a música estava, inicialmente, ligada à religião. No período compreendido entre sua chegada e expulsão, em 1759, os jesuítas demonstraram estar extremamente preocupados com a educação, deixando em seu rastro 11 colégios e seis seminários. (OLIVEIRA, 2007, p.5).

A literatura sobre a educação musical, de forma geral, aponta como outro importante marco os anos 1930, quando a música, como parte do projeto político educacional do então presidente Getúlio Vargas, torna-se obrigatória em todos os níveis escolares (SOUZA, 2007, p.13). Como bem lembra Fuks, “o estudo da história [...] aponta para um longo percurso de criação das condições para o que iria ser instituído nos anos 30" (FUKS, 2007, p.18). Assim, fica claro que nenhum desses marcos estabeleceu-se exclusivamente por decreto e, tal qual o movimento que levou à Lei 11.769/08, são fruto de longos processos.

Interessa-nos aqui discutir em especial uma questão que permeia todoopercurso histórico sobre o ensino de música nas escolas, que é a formação do professor de música. A Lei 11.769/08, que dispõe sobre a obrigatoriedade do ensino de música nas escolas como componente curricular da disciplina de artes, levanta novamente essa discussão e de forma bastante contraditória. Isso porque a lei teve veto ao artigo $2^{\circ}$ que previa a necessidade de formação específica para o professor de música. Seria esse um indício da volta à tão criticada polivalência do professor de arte, que continua tendo que dar conta, agora de forma "obrigatória”, de conteúdos da área da música mesmo sem formação específica?

A história da educação musical no Brasil nos mostra que a música nas escolas sempre foi um campo de disputa entre aqueles que entendem a música como área de conhecimento específico e aqueles que a entendem como lazer ou recreação. Quais seriam as consequências do veto ao artigo $2^{\circ}$ através do qual não se tem a obrigatoriedade de formação específica para o professor de música? Como garantir, de fato,aobrigatoriedade da educação musical nas escolas de ensino básico brasileiras? Como afirmado, e de acordo com Saviani, "a organização escolar não é obra da legislação. Ambas interagem no seio da sociedade que produz uma e outra" (SAVIANI, 1980, p.154). 


\section{A formação do professor de música: antigas questões}

Conforme nos demonstra Fuks (2007), o projeto de educação musical liderado por Villa-Lobos nos anos 1930, como parte do projeto político educacional do presidente Vargas, foi inspirado no modernismo da década anterior. A autora nos conta que músicos como o maestro Francisco Braga, o compositor Sylvio Salema Garção Ribeiro e D. Eulina de Nazareth, filha do compositor Ernesto Nazareth, formaram já na década de 1920 uma comissão para elaborar um programa de música para as escolas do Rio de Janeiro, então Distrito Federal, o que indica

a existência, nos anos 20, de uma política de educação musical e de um interesse governamental a respeito da sistematização dessa forma de ensino. (FUKS, 2007, p.20).

Porém, o crédito ao projeto de Villa-Lobos como um marco para o ensino de música nas escolas brasileiras deve-se a alguns fatores, entre eles estão a abrangência da proposta, que não atendia somente ao Distrito Federal, mas a todo o território nacional, e à preocupação com a formação dos professores.Através da Superintendência da Educação Musical e Artística (SEMA) Villa-Lobos, a reboque do Decreto 19.890 de 18 de abril de 1931 que instituiu o ensino obrigatório de Canto Orfeônico no Município do Rio de Janeiro,foi criado oCurso de Orientação e Aperfeiçoamento do Ensino de Música e Canto Orfeônico para a formação dos professores.

Não obstante toda a complexidade do momento histórico quando esse projeto de educação musical nas escolas se desenvolveu e todas as suas implicações ${ }^{1}$, a preocupação no desenvolvimento de um projeto ampara-

${ }^{1}$ Sobre isso, ver Souza (2007). do por leique pretendia garantir a educação musical nas escolas em âmbito nacional, a preocupação com a elaboração de um projeto político pedagógico para a educação musical e a preocupação com a formação docente foi um ganho, naquele momento, para a história da educação musical brasileira.

Por outro lado, verificamos, no decorrer da história, que embora a preocupação com a formação docente sempre se faça presente, é uma questão que permanentemente vem enfrentando desafios. Se observarmos documentos e Leis que amparam o ensino de música nas escolas, veremos que a discussão sobre a formação do professor de artes sempre foi tema de debate.

Os Parâmetros Curriculares Nacional para as Artes (PCN-Artes), por exemplo,como crítica ao projeto de Villa-Lobos,observa que esse projeto "esbarrou em dificuldades práticas na orientação de professores e acabou transformando a aula de música numa teoria musical baseada nos aspectos matemáticos e visuais do código musical” (PCN, 1997, p.22). Sobre a introdução da educação artística no currículo escolar, enaltece as artes como componente formador, e critica a polivalência do professor.

O resultado dessa proposição foi contraditório e paradoxal. Muitos professores não estavam habilitados e, menos ainda, preparados para o domínio de várias linguagens, que deveriam ser incluídas no conjunto das atividades artísticas. (p.24).

\section{E explica:}

De maneira geral, entre os anos 70 e 80, os antigos professores de Artes Plásticas, Desenho, Música, Artes Industriais, Artes Cênicas e os recém-formados em Educação Artística viram-seresponsabilizados por educar os alunos (em escolas de ensino médio) em todas as linguagens artísticas, configurando-se a formação do professor

Olhar de professor, Ponta Grossa, 15(2): 371-382, 2012. Disponível em <http://www.uepg.br/olhardeprofessor> 
polivalente em Arte. Com isso, inúmeros professores deixaram as suas áreas específicas de formação e estudos, tentando assimilar superficialmente as demais, na ilusão de que as dominariam em seu conjunto. A tendência passou a ser a diminuição qualitativa dos saberes referentes às especificidades de cada uma das formas de arte e, no lugar destas, desenvolveu-se a crença de que bastavam propostas de atividades expressivas espontâneas para que os alunos conhecessem muito bem música, artes plásticas, cênicas, dança,etc. (PCN, 1997, p.24).

Mais adiante, aponta o movimento Arte-Educação, dos anos 1980, como um importante movimento que

permitiu que se ampliassem as discussões sobre a valorização e o aprimoramento do professor, que reconhecia o seu isolamento dentro da escola e a insuficiência de conhecimentos e competência na área. (p.25).

Apesar da discussão empreendida pelos PCN, ele mesmo foi alvo de críticas. Penna, por exemplo,observa nosPCNs uma “falta de clareza acerca da formação do professor de arte, cuja qualificação não é indicada com precisão” (2003, p.24). Dessa forma, conforme Penna, osPCNs ao não apontar com clareza qual seria a formação do professor deixa em aberto se essa formação seria geral, abordando todas as linguagens artísticas, ou específica. Segundo Penna

Uma questão crucial, portanto, é o professor que irá colocar em prática os PCN-Arte: qual deverá ser a sua qualificação? A característica geral da proposta, que se direciona para o resgate dos conhecimentos específicos da arte, a complexidade dos conteúdos nas diversas modalidades artísticas, tudo isso parece indicar a necessidade de professores especializados em cada linguagem. Mas, na verdade, não há definições claras sobre a formação do professor de Arte, nem nos PCN, nem na atual Lei de Diretrizes e Bases (LDB). Por conseguinte, como muitas vezes a contratação de professores está submetida à lógica de custos e benefícios, acreditamos que dificilmente as escolas contarão - a curto ou médio prazo - com professores especializados em cada uma das quatro modalidades artísticas dos PCN-Arte. (PENNA, 2001, p.51).

No contexto atual, com a Lei 11.769/08, a música ganha status de componente curricular obrigatório, porém ainda não é uma disciplina. Com o veto ao artigo $2^{\circ}$, que previa a necessidade de formação específica do professor de música, nos parece que permanecemos com as mesmas indagações e críticas como as expostas anteriormente e com a necessidade de debater sobre a questão da formação de professores frente à Lei 11.769/08.

Nessa direção, percebemos a existência de preocupações e considerações sobre as implicações da Lei 11.769/08 através de produções bibliográficas efóruns de debate sobre o tema, como os promovidos pela Associação Brasileira de Educação Musical (ABEM). ${ }^{2}$

Apenas como indicação,podemos citar os livros organizadospor Santos (2011), que discute a Lei 11.769 frente às múltiplas possibilidades da presença da música nas escolas; Penna (2010), que através de uma coletânea de artigos também discute possibilidades práticas para a implementação da Lei 11.769/08; eo livro organizado por Santos e Batista (2011) com propostas práticas ao professor de música e como material de apoio à implementação da Lei.

\footnotetext{
${ }^{2} \mathrm{O}$ último Congresso Anual da ABEM, realizado em 2011 em Vitória/ES, por exemplo, teve como tema "A Educação Musical no Brasil do Século XXI”.
} 
Ainda com o objetivo de contribuir com o debate sobre a implementação da Lei 11.769/08, citamos o artigo de Sobreira (2008) "Reflexões sobre a obrigatoriedade da música nas escolas públicas”, que aponta, naquele momento, a existência de um incipiente número de publicações sobre o assunto, apesar do já intenso debate. A autora indica ainda alguns entraves para a aplicação da Lei, como a falta de docentes com a formação necessária.

Em um importante debate, Figueiredo e Pereira (s.d.) observam que a Lei 11.769/08 altera a LDB de 1996 apenas no parágrafo referente às artes, o que significa que o veto ao artigo que trata sobre a obrigatoriedade da formação específica ao professor não indicaria a não necessidade dessa formação, uma vez que a obrigatoriedade do diploma de licenciatura estaria assegurada pelo artigo 62 da LDB. Assim, a conclusão dos autores é a de que "seguindoesta orientação, para ensinar música na escola,é preciso ser licenciado em música” (s.d., p.2). A dúvida que permanece é: se, conforme a lei, a música é conteúdo curricular, porém não exclusivo, da disciplina de artes, então, todo professor de artes teria também de ser licenciado em música ou a escola deve se incumbir de oferecer dois professores licenciados para atuar na disciplina de artes? Considerando o artigo 62 que afirma

A formação de docentes para atuar na educação básica far-se-á em nível superior, em curso de licenciatura, de graduação plena, em universidades e institutos superiores de educação, admitida, como formação mínima para o exercício do magistério na educação infantil e nas quatro primeiras séries do ensino fundamental, a oferecida em nível médio, na modalidade Normal. (BRASIL, 1996).
Será que podemos garantir que essa licenciatura seja de fato em música?

Em outro sentido, o veto ao artigo segundo da Lei ${ }^{\circ}$ 11.769/08 na interpretação de Alvarenga e Mazzotti (2011),

ao sugerir que músicos e artistas, sem a formaçãoacadêmica ou oficial, desde que reconhecidos pelos seus grupos, possam ministrar oconteúdo de música na escola regular, descredenciam-se os professores de músicaformados nos cursos de licenciatura (p.69)

e concluem que, nesse caso,

distorcem-seas disposições legais que regem a formação em nível superior, afirmando que alguém nãolicenciado em determinada área de conhecimento pode ensiná-la.

Como podemos perceber, a lei proporciona diferenciadas interpretações.

Conforme Penna, entendemos que a Lei 11.769/08 representa um momento de transição, que necessita de ações que a tornem realidade.

A Lei 11.769/2008 fortalece essas conquistas, e com ela abrem-se as múltiplas possibilidades para a área de educação musical, que se encontra em um momento histórico de transição, de extrema importância quanto aos reais efeitos dessa determinação legal, em processo de implementação. Entretanto, é importante ter consciência de que as leis e outros dispositivos regulamentadores não são dotados de uma 'virtude intrínseca' capaz de realizar mudanças na organização e na prática escolar. Nesse sentido, não cabe esperar que essa nova lei gere automaticamente transformações na prática pedagógica cotidiana. A realização efetiva das possibilidades que se abrem para a música na escola depende de inúmeros fatores, inclusive do modo como atuamos concretamente nos múltiplos espaços possíveis. (Penna, 2010, p.141).

Olhar de professor, Ponta Grossa, 15(2): 371-382, 2012. Disponível em <http://www.uepg.br/olhardeprofessor> 
Debater a questão da formação do professor de música, aquele que vai efetivamente fazer acontecer os dispositivos da Lei 11.769/08, sem dúvida, é o desafio que temos pela frente. Porém, acreditamos que as leis só se sustentam por ações que as tornem viáveis. Indo além, acreditamos que para que tais ações sejam efetivas é necessário que conheçamos a realidade das escolas, em especial, aquelas localizadas no interior do país, pois são essas, indiscutivelmente, as que dispõem de menores recursos materiais e humanos.

Nesse sentido, autores como Dozza Subtil (2009), a partir de pesquisa de campo, revelam a falta de professores de fato habilitados para trabalhar com a disciplina artes nas escolas. A autora aponta a

falta de formação específica dos professores, a ausência de concepção de trabalho artístico e, em decorrência, um visível reducionismo no encaminhamento do trabalho com arte nesse segmento escolar. (DOZZA SUBTIL, 2009, p.185).

o que seria, segundo a autora, um resquício da Lei 5.692/71 que traz a "visão da arte como atividade, polivalência e livre-expressão" (idem). No mesmo sentido, Sobreira (2008) indica que entre as dificuldades para se trabalhar o conteúdo musical nas escolas da rede oficial, estão a falta de docentes e a formação necessária.

Por tudo o que foi comentado até aqui, entendemos a necessidade de se conhecer a realidade das escolas e, principalmente, o que pensam professores, diretores e alunos a respeito da música nas escolas. Como docente de uma universidade federal na região da Costa Verde Sul Fluminense, junto a um grupo de pesquisa formado por professores e alunos do curso de pedagogia dessa instituição, realizamos pesquisa de campo em quatro municípios vizinhos. A pesquisa nos permitiu uma maior compreensão das reais possibilidades de se efetivar a educação musical nas escolas públicas e entender a formação dos professores na área da música como condição para isso. É o que relataremos a seguir.

\section{A realidade em escolas da CostaVerde Sul Fluminense: um estudo de caso}

Entre julho de 2011 e julho de 2012, tivemos a oportunidade de desenvolver um estudo em escolas da Costa Verde Sul Fluminense, em especial, nos municípios de Paraty, Angra dos Reis, Rio Claro e Mangaratiba. Através desse estudo, buscamos entender os reflexos da Lei 11.769/08 a partirdaquele momento - agosto de 2011 -,quando findava o prazo estipulado para sua efetiva implementação. ${ }^{3}$

Visitamos cerca de 20 escolas nos quatro municípios e em entrevistas com seus diretorese com a aplicação de um questionário acerca de 80 professores, tivemos um panorama sobre questões a respeito da obrigatoriedade do ensino de música nas escolas. Foram entrevistados professores de diversas disciplinas, e não só de artes. Isso porque nossa intenção era de fazer uma avaliação de como a educação musical é compreendida por todo o corpo docente das escolas. Assim como Sobreira (2008) e conforme poderemos observar adiante, acreditamos que conhecer a concepção que se tem sobre o ensino da música é fundamental para compreender as formas de inserção da música nas escolas.

\footnotetext{
${ }^{3}$ Trata-se da pesquisa "Implementação da Lei 11.769: construção de uma proposta de formação inicial e continuada para professores da Rede Pública da Costa Verde Sul Fluminense na área da Educação Musical”, que teve apoio da FAPERJ na modalidade APQ1.
} 
O resultado que obtivemos através desse estudo nos indicou uma variada gama de concepções sobre o ensino de música, que se enquadram, de forma geral, nas três representações destacadas a seguir:

1. A música como um componente auxiliar aos professores de diversas disciplinas, como química, matemática e história. Nesse caso, os professores entendem que a obrigatoriedade do ensino de música nas escolas significa capacitar os professores de diversas disciplinas no sentido de oferecer-lhes ferramentas "musicais" que os auxiliem no desenvolvimento de seus conteúdos específicos em sala de aula.

2. A música como um elemento lúdico no espaço escolar. Nesse sentido, o papel da música na escola e das artes em geral seria o de proporcionar aos alunos um momento de descontração, para que os conteúdos das demais disciplinas possam se tornar menos "pesados". O professor de música é entendido como aquele capaz de desenvolver atividades práticas, como a criação de bandas musicais ou coros.

3. A música como uma área de conhecimento específico. Nessa concepção,o professor de música necessitaria de formação específica e o objetivo da educação musical seria colaborar para uma formação mais ampla do aluno, desenvolvendo capacidades específicas baseadas na aplicação prática de conceitos e respeitando o estágio de desenvolvimento do aluno.

Quantitativamente, tivemos o seguinte resultado:
Figura 01- música nas escolas

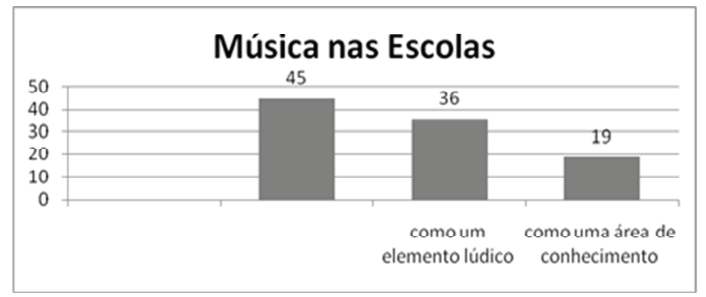

Contraditoriamente, apesar de a música nas escolas ser entendida pela maioria dos professores e diretores como um componente auxiliar ou como um elemento lúdico, conhecimentos bastante específicos foram relacionados no questionário aplicado, onde a teoria musical e a história da música são destaque:

As atividades práticas e trabalhos em grupo foram considerados prioritários, como mostra a figura a seguir:

Figura 02 - conteúdos da educação musical

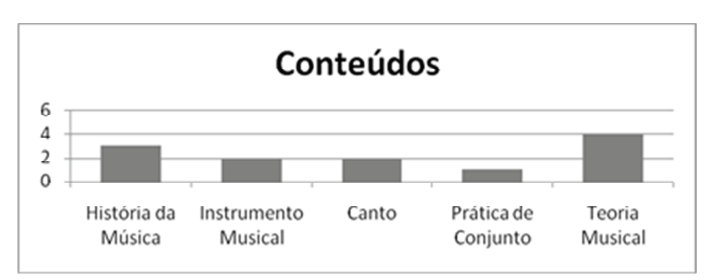

Figura 03 - procedimentos didáticos

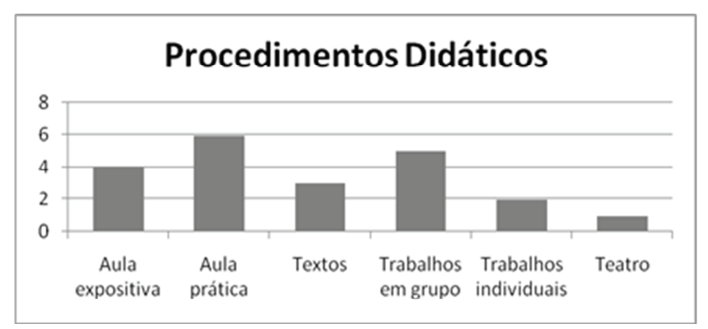


Sobre a Lei 11.769/08, alguns diretores a desconheciam, outros tinham conhecimento, mas não sabiam bem como aplicá-la, e um município em particular - Angra dos Reis - já havia tomado medidas efetivas para sua implementação. ${ }^{4}$

Das escolas que já desenvolviam alguma atividade musical, que corresponde a cerca de $30 \%$ do conjunto de escolas visitadas, não foi raro encontrar situações onde funcionários das escolas com alguma experiência em atividades práticas musicais na comunidade ou que possuíam alguma habilidade específica foram designados ao ensino de música em atividades extraclasse.

A representação do professor de música, de acordo com o conjunto de professores e diretores consultados, apresentou-se da seguinte forma:

Figura 04 - representação do professor de música

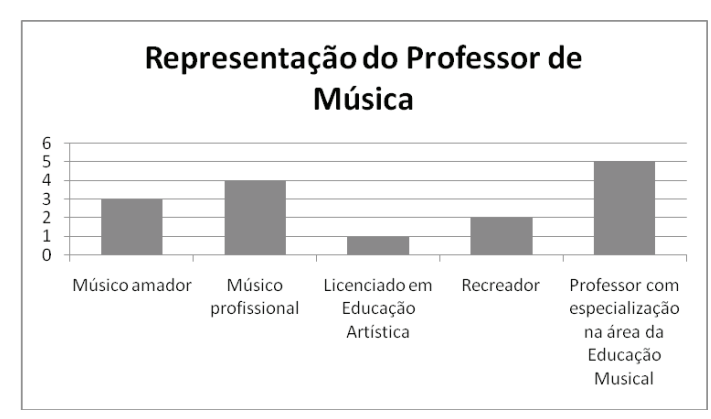

A maioria dos professores que responderam a nosso questionário entendeu que as atividades com música na escola podem ser desenvolvidas porprofessores de qualquer outra disciplina, desde que receba alguma formação específica para esta atuação. Essa ideia vai ao encontro da forma como esses

\footnotetext{
${ }^{4}$ No caso de Angra dos Reis, foi criado um polo musical, com professores específicos, para atender alunos de determinada região. A coordenadora de música do município nos informou que o projeto é o de criar um polo para atender cada região escolar.
}

professores compreendem o papel da educação musical na escola,ou seja, como um componente auxiliar aos professores de diversas disciplinas.

Correspondendo também à situação encontrada, músicos amadores atuantes na região estão trabalhando como professores de música, esses, muitas vezes empregados na escola como zeladores ou outras funções. $20 \%$ dos professores indicaram o músico amador como perfil ideal para o professor de música. De forma muito curiosa, o professor licenciado em educação artística ficou em último lugar, perdendo inclusive para aquele que teria o perfil de recreador.

De forma não esperada, conteúdos teóricos como a história da música e a teoria musical foram indicados como prioritários, ao mesmo tempo em que as aulas práticas ganharam destaque.

Correspondendo ao respondido através dos questionários, foi comum encontrar na fala dos diretores quando perguntados sobre o que pensam a respeito da formação dos professores de música e o papel da educação musical nas escolas, respostas como as seguintes:

As crianças aprendem muito com a música, é até mais fácil aprender cantando do que fazendo cópias. [...] É preciso melhorar a formação dos professores para usarem mais a música em sala de aula.

O professor de espanhol sempre procurou focar a música. Eu, quando estava em sala de aula, sempre procurei focar a música, atrelar a música a um texto [...]. Pegava uma letra para trabalhar a gramática [...]. Eu só tenho o gostinho pela música, agora,conhecimento nenhum.

A ideia do colégio é esta: não existe um professor [de música]. Tem um professor de história que colocou a letra "Que país é esse?” do Legião Urbana [...]. Isso [a 
educação musical na escola] cabe ao professor de história? Não, cabe a todo mundo.

E a música não vai servir só para cumprir a Lei, é pro dia-a-dia mesmo. Tá tão difícil manter o aluno em sala de aula. [...] Eu acho assim, que a música consegue prender. [...] Dando aula de história, dando aula de português mais ainda né?

\begin{abstract}
A gente tem um professor voluntário, ele vem aqui e ensina mais ou menos alguns tons, faz algum trabalho com as crianças, mas não é coisa efetiva, não. Quando tá perto de 7 de setembro ou quando a gente tem alguma comemoração pra fazer, esse professor dá noção.
\end{abstract}

Esse breve relato de pesquisa nos aponta alguns dos desafios que teremos que enfrentar para o cumprimento da Lei 11.769/08 em âmbito nacional. Em algumas escolas, no interior do estado do Rio de Janeiro, encontramos situação bastante crítica em relação a recursos materiais e humanos. Sem entrar nesse mérito da questão e nos restringindo apenas às considerações sobre a educação musical, a partir do que foi exposto,destacamos alguns pontos que nos parecem relevantes para o debate:

1. O conhecimento da Lei 11.769/08 e de seus dispositivos não chegou para significativa parte dos diretores e professores das escolas visitadas;

2. A grande maioria de diretores e professores não entende a educação musical como uma área de conhecimento específico, apesar de apontar a necessidade de alguma formação ou experiência musical para aquele que será o responsável por desenvolver atividades musicais na escola;

3. Na falta de professores com formação específica, estão sendo direcionados para a prática da música nas escolas funcionários com funções variadas que não são contratados como professores;

4. A expectativa de grande parte dos professores das escolas é a de que eles mesmos recebam instrução necessária para poder utilizar a música como recurso didático em suas disciplinas.

A discussão sobre a importância da música para formação humana é antiga. Violeta Gainza (2011), fundadora do Fórum Latino-Americano de Educação Musical, diz que essa discussão é algo que já deveria ter sido superado. Porém, ela traz a reboque outra questão de igual importância: quem é o profissional que irá colocar não só o ensino de música, mas todo um processo de educação musical em prática? Violeta Gainzanos responde: "necessitamos de professores, de fato, especializados em música” (p.40). Assim, temos pela frente a missão de retomar o debate de antigas questões que ainda não foram superadas e que hoje encontram novos desafios.

O breve relato apresentado nos indica a possibilidade de se encontrar uma diversidade de concepções sobre o ensino de música nas escolas Brasil afora. Entendemos que a aprovação da lei, e mesmo a disponibilização de recursos materiais, não são ações suficientes para que se possa garantir a aplicação da Lei 11.769/08, considerando todo o processo histórico percorrido pela educação musical até seu reconhecimento como área de conhecimento específico.

Interessante observar o caso relatado pela diretora de um colégio estadual sobre o uso do material didático distribuído às escolas pela Secretaria Estadual de Educação. ${ }^{5}$

\footnotetext{
${ }^{5}$ Trata-se do kit MPB nas escolas, elaborado pelo Instituto Cravo Albin, comprado pelo Governo do Estado do Rio de Janeiro e já distribuído às escolas estaduais. Sobre isso, ver:<http://institutocravoalbin.com.br/ mpb-nas-escolas>.Acesso em:11 dez. 2011.
} 
Quando perguntada se o material estaria atendendo as necessidades da escola, a diretora informou: "não, é mais um material informativo, de divulgação dos tipos musicais da MPB”. Quando perguntada se houve algum treinamento para uso desse material, a diretora respondeu que não, mas que soube que "determinadas escolas foram atendidas com treinamento para uso do material" e que

o material está sendo usado por quem tem interesse. Há o professor que tem interesse em trabalhar a história, por exemplo, do samba, ali tem toda a história, algumas letras, alguns autores, mas nãoligado diretamente ao currículo.

Se buscarmos conhecer a história apenas pela leitura das leis produzidas, teremos uma visão bastante distorcida da realidade. Conformar-nos apenas com a sanção de leis que poderiamtrazer benefícios à população é correr o riscode anula-las. Para que se efetivem é necessário, em primeiro lugar, que conheçamos a realidade onde essa lei será aplicada, e em segundo, ações e investimento material e humano para que ela se realize. Nesse sentido, destacamos a necessidade de ações educativas que qualifiquem todo o processo histórico em que a educação musical passa a ser reconhecida como área de conhecimento específico. É o reconhecimento da música como um elemento essencial à formação humana, e a necessidade de formação para o professor de música, o primeiro passo para que a Lei 11.769/08se torne a realidade nas escolas brasileiras.

A partir dos dados levantados, e em consonância com as reflexões de Sobreira (2008), percebemos que as diferentes concepções sobre a música nas escolas e sobre o professor de música contradizem importantes conquistas realizadas através da história onde a música se afirma como área de conhecimento específico necessitando assim, a Educação Musical, de professores com conhecimentos específicos. Sobreira diz que "as diferentes concepções acabampor comprometer a inserção da música nas escolas, uma vez que cada concepção corresponde ametodologias e formação docentes específicas” (p.45). É por esse motivo que entendemos que conhecer a forma como a escola em sua integralidade concebe a educação musical é fundamental para a elaboração de ações que contribuam para a efetivação da educação musical nas escolas. É isso o que buscamos fundamentalmente demonstrar pelo exposto.

\section{Considerações finais}

Com base nesse texto, buscamos mostrar, mesmo que de forma breve, que a educação musical no Brasil vem percorrendo uma longa trajetória na busca por ser reconhecida como área de conhecimento. A produção acadêmica de professores-pesquisadores de diversos programas de pós-graduação em música espalhados pelo país, assim como a longa trajetória da Associação Brasileira de Educação Musical (ABEM), entre outros, representa essa conquista. O debate dessa questão, associado ao debate sobre a formação do professor de música, se faz presente também na interpretação de decretos e leis e em documentos como os PCNs. A Lei 11.769/2008 faz parte desse processo no sentido de reconhecer a necessidade da música como um elemento indispensável à formação humana. Porém, no nosso entender, deforma contraditória, o veto ao artigo $2^{\circ}$ que dispensa ao professor de música uma formação específica representa um retrocesso. Entendemos que o veto expressa uma negação ao reconhecimento da música como área de conhecimento. Com isso, não se está negando que recreadores ou músicos amadores 
possam desenvolver atividades extremamente gratificantes para os estudantes do ensino básico. Mas a intencionalidade de uma ação educativa na área da música vai bem além do que uma atividade recreativa. Como disse Gainza, essa é uma discussão que já deveria ter sido superada.

Buscamos ainda mostrar pelos dados apresentados que o simples fato da existência da lei, mesmo que haja recursos materiais, não é suficiente para o seu cumprimento. É preciso que as escolas conheçam e, fundamentalmente, reconheçam o papel da educação musical em suas atividades, e a consequente necessidade da formação específica para o professor de música.

\section{Referências}

ALVARENGA, C. H.; MAZZOTTI, T. B. Educação musical e legislação: reflexões acerca do veto à formação específica na Lei 11.769/2008. Opus, Porto Alegre, v. 17, n. 1, p. 51-72, jun. 2011.

BRASIL. Lei $\mathrm{n}^{\circ} 11.769$, de 18 de agosto de 2008. Altera a Lei $\mathbf{n}^{0} \mathbf{9 . 3 9 4}$, de 20 de dezembro de 1996 para dispor sobre a obrigatoriedade do ensino da música na educação básica. Diário Oficial da União, Brasília, ano CXLV, n. 159, seção 1, p. 1, 19 ago. 2008. Disponível em: <http://www. in.gov.br/imprensa/visualiza/index.jsp?jorna $\mathrm{l}=1$ \&pagina $=1$ \&data $=19 / 08 / 2008>$. Acesso em: 20 out.2012.

Lei de Diretrizes e Bases - Lei $n^{\circ}$ 9.394, de 20 de dezembro de 1996. Estabelece as diretrizes e bases da educação nacional. 20 dez. 1996. Disponível em: <http://www. jusbrasil.com.br/legislacao/109224/leide-diretrizes-e-bases-lei-9394-96\#art62>. Acesso em: 20 out.2012.
SUBTIL, M. J. D. Educação e arte: dilemas da prática que a história pode explicar. Práxis Educativa. Ponta Grossa, v. 4, no 2, p. 185194, jul-dez, 2009. Disponível em: <http:// redalyc.uaemex.mx/src/inicio/ArtPdfRed. jsp ?iCve=89412348009 $>$. Acesso em: 20 out.2012.

FIGUEIREDO, S. L. F.; PEREIRA, G. V. As orientações legais para o ensino de música nas séries iniciais do Ensino Fundamental nos estados da Bahia, Rio Grande do Norte e Sergipe. s.d. Disponível em: <http://www. ceart.udesc.br/revista_dapesquisa/volume4/ numero1/musica/asorientacoeslegais.pdf>. Acesso em: 20 out.2012.

FUKS, R. A. Educação musical na era Vargas: seus precursores. In: OLIVEIRA, A.; CAJAZEIRA, R. Educação musical no Brasil. Salvador: P\&A, 2007, p. 18-23.

GAINZA, V. H. Fala, mestre! Revista Nova Escola, abril 2011, p.38-40.

OLIVEIRA, A. Aspectos históricos da educação musical no Brasil e na América do Sul. OLIVEIRA, A; CAJAZEIRA, R. Educação musical no Brasil. Salvador: P\&A, 2007, p. 3-12.

\section{PARÂMETROS CURRICULARES}

NACIONAIS, 1997. Disponível em: <http:// portal.mec.gov.br/seb/arquivos/pdf/livro06. pdf>. Acesso em: 09 jun.2011.

PENNA, M. É este o ensino de arte que queremos? uma análise das propostas dos Parâmetros Curriculares Nacionais, 2001. Disponível em: <http://www.cchla.ufpb.br/ pesquisarte/Masters/e_este_o_ensino.pdf>. Acesso em: 15 jun. 2012.

A dupla dimensão da política educacional e a música na escola: analisando a legislação e termos normativos. Revista da ABEM, Porto Alegre, n. 10, p. 19-28, mar. 2004.

Olhar de professor, Ponta Grossa, 15(2): 371-382, 2012. Disponível em <http://www.uepg.br/olhardeprofessor> 
PENNA, M. Música(s) e seu ensino. Porto Alegre: Sulina, 2010.

SANTOS, R. M. S. (Org.). Música, cultura e educação: os múltiplos espaços de educação musical. Porto Alegre: Sulina, 2011.

SANTOS, A. K. A.; BATISTA, H. S. (Orgs.) A música na educação básica: material de apoio à implantação da Lei 11.769/08. Salvador: Edufba, 2011.

SAVIANI, D. Educação: do senso comum à consciência filosófica. São Paulo: Cortez, Autores Associados, 1980.

SOBREIRA, S. Reflexões sobre a obrigatoriedade da música nas escolas públicas. Revista da ABEM, Porto Alegre, n. 20, p. 45-52, set. 2008.

SOUZA, J.A Educação musical no Brasil dos anos 1930-45. In: OLIVEIRA, A.; CAJAZEIRA, R. Educação musical no Brasil. Salvador: P\&A, 2007, p. 13-17.

Enviado em: 12/07/2012

Aceito em: 05/11/2012 